\title{
Prevalence of Cardiovascular Disease Risk Factors in Shaqra, Saudi Arabia
}

Feras Mansour Almarshad $^{1 *}$, Abdulaziz Abdulrahman Alrashed ${ }^{2}$,

Khalid Ibrahim Aljammaz ${ }^{2}$, Ali Mohammed Alduhayshi ${ }^{2}$, Jaber Saleh Alhadlaq ${ }^{2}$

${ }^{1}$ Department of Internal Medicine, ${ }^{2}$ Medical Student, College of Medicine,

Shaqra University, Shaqra, Saudi Arabia

*Corresponding Author: Feras Mansour Almarshad-ORCID ID: https://orcid.org/0000-0002-9468-1489,Email: feras-mmm@ hotmail.com

\begin{abstract}
Background:According to the report of World Health Organization (WHO), cardiovascular diseases (CVDs) accounted for most noncommunicable disease (NCD) deaths (17.5 million NCD deaths) during 2012 worldwide. Surveillance of CVD risk factors is a key strategy for effective CVD prevention.

Aim:To identify the extent of CVD risk factors of developing cardiovascular disease events among Shaqra population of Saudi Arabia.

Method:This community-based cross-sectional study was conducted on a total of 369 participants including 267 (72.3\%) males and 102 (27.6\%) females aged 18-45 years from Shaqra City of Saudi Arabia. Blood Pressure, BMI, blood glucose, smoking status and family history of CVD risk factors were estimated.

Results:Prevalence of hypertension was $10.3 \%$ and diabetes $1.6 \%$. Tobacco consumption was $24.8 \%$. Obesity was $23.30 \%$. Family history of HTN and DM was $50.09 \%$.

Conclusion:High prevalence of hypertension, obesity and tobacco consumption was seen in Shaqra population which will predispose to CVD risk. Campaigns to raise the awareness of CVD risk factors will boost the quality of life of the peoples and will add years to live.
\end{abstract}

Key Words: Cardiovascular disease, hypertension, diabetes mellitus, smoking, obesity.

\section{INTRODUCTION}

Cardiovascular diseases (CVDs) are the first leading cause of death worldwide ${ }^{(1)}$. According to the World Health Organization (WHO) in 2011, CVDs accounted for 17.3 million deaths per year ${ }^{(2)}$, and the ratio of deaths caused by CVDs among all deaths increased from 1:5 in 1990 to $1: 4$ in $201{ }^{(3)}$. CVDs risk factors such as smoking, obesity, BMI and lifestyle are most common causes for life-threatening diseases ${ }^{(4)}$. These risk factors can be controllable like hypertension, diabetes mellitus, obesity, and hyperlipidemia by lifestyle modifications (5). Therefore, caring for this risk factor is one of the important goals in preventing CVD (6). Various worldwide studies assessed the prevalence of CVD risk factors. Almost $50 \%$ of the deaths of those aged below 70 were found to be attributed to CVD deaths, while in western countries, it is about $25 \%$, a substantial difference ${ }^{(7)}$. Lifestyle development in childhood and adolescence reduces mortality from CVD and may prevent long-term disability. CVD are asymptomatic; therefore, preventive measures are very important factor ${ }^{(8)}$. One systemic review indicates high prevalence of CVD risks in gulf countries ${ }^{(9)}$. One study indicates the prevalence of CVD mortality rate in the Kingdom of Saudi Arabia is $46 \%{ }^{(10)}$. This significantly high percentage might be related to the lack of awareness of cardiovascular risk factors. Sedentary life, smoking and high consumption of fast food have increased in community, despite the fact that they can be prevented ${ }^{(11,12)}$. In Jeddah, research had studied the prevalence of undiagnosed CVD risk factors in adults aged 20-40 and indicated that CVD risk factors are common in young adults ${ }^{(13)}$.
In this study, we determined the common prevalence factors for the CVDs including blood pressure, blood glucose, obesity, and smoking during the "Public Awareness Programme" organized by the medical students of the College of Medicine at Shaqra at Al-Basateen Mall in February 2019.

\section{METHODS}

A cross-sectional study was conducted in February 2019 where data was collected from a "Public Awareness Programme" campaign conducted at AlBasateen Mall, Shaqra city, Saudi Arabia. We briefed male and female visitors of Al-Basateen mall about cardiovascular risk factors.

\section{Ethical consideration:}

The Institutional Ethical Committee approved the research protocol with approval number: SUCOM/LIRB/2019-04).

A brief questionnaire was answered by each male and female participant about medical history, smoking status, medications, and family history. Blood pressure (BP) measurement was taken as per the American Heart Association recommendations ${ }^{(14)}$. BP readings were obtained for each male and female participant. The analysis was based on JNC-8 recommendations to define $\mathrm{HBP}$. We considered HBP if the systolic blood pressure (SBP) exceeded $140 \mathrm{~mm}$ $\mathrm{Hg}$ and/or the diastolic blood pressure (DBP) exceeded $90 \mathrm{~mm} \mathrm{Hg}{ }^{(15)}$.

Body mass index (BMI) of the participants was calculated as weight $(\mathrm{kg})$ divided by the square of height $\left(\mathrm{m}^{2}\right)$. Participants were categorized according 
to World Health Organization (WHO) categorization as follows: underweight (BMI $<18.5 \mathrm{~kg} / \mathrm{m}^{2}$ ), normal $\left(\mathrm{BMI}=18.5-24.9 \mathrm{~kg} / \mathrm{m}^{2}\right)$, overweight $(\mathrm{BMI}=25-$ $\left.29.9 \mathrm{~kg} / \mathrm{m}^{2}\right)$, obese class I $\left(\mathrm{BMI}=30-34.9 \mathrm{~kg} / \mathrm{m}^{2}\right)$, obese class II $\left(\mathrm{BMI}=35-39.9 \mathrm{~kg} / \mathrm{m}^{2}\right)$, and obese class III $\left(\mathrm{BMI} \geq 40 \mathrm{~kg} / \mathrm{m}^{2}\right)^{(16)}$.

Blood glucose level of the participants was measured using a manual glucometer. All participants were asked about their last meal, to categorize readings as fasting or random, we depended on the 8$\mathrm{h}$ limit. All participants were labeled according to the cutoff points established by the WHO, which are defined as follows: $126 \mathrm{mg} / \mathrm{dL}$ for fasting and 200 $\mathrm{mg} / \mathrm{dL}$ for random ${ }^{(17)}$

\section{Statistical analysis}

IBM SPSS version 20 was utilized for data entry, management, and analysis. Descriptive statistics were used in the form of frequencies and percentages for categorical data, mean and standard deviation for quantitative data. To compare qualitative variables, we utilized the Chi-square test and we used a $\mathrm{P}<0.05$ to determine statistical significance.

\section{RESULTS}

The study sample was 369 participants. The demographic characteristics and risk factors frequency calculations for the participants are presented in Table 1. 197 (53.38\%) participants had an abnormal BMI of $\geq 25 \mathrm{~kg} / \mathrm{m}^{2}$ and $86(23.30 \%)$ participants had classified as obese (figure 1).

There was a statistically significant $(\mathrm{p}=0.026)$ relationship between gender and abnormal body weight as seen in table 2 as females represent a higher proportion of obesity and overweight categories when compared to males.

$81(24.8 \%)$ participants were smokers. The firstdegree relative family history of DM and HTN combined was present in $188(50.09 \%)$ participants (figure 2). 62 (16.8\%) participants were reported having a history of high cholesterol and/or triglyceride levels. $6(1.6 \%)$ participants were diagnosed with diabetes mellitus and $38(10.3 \%)$ were diagnosed with hypertension.

Table 1: Parameters values of participants

\begin{tabular}{|l|l|}
\hline \multicolumn{1}{|c|}{ Parameters } & \\
\hline Age range (\%) \\
\hline Male & $18-45$ \\
\hline Female & $267(72.4 \%)$ \\
\hline Blood Pressure Measurements: & $102(27.6 \%)$ \\
SBP and/or DBP $<140 / 90 \mathrm{mmHg}$ & \\
SBP and/or DBP $\geq 140 / 90 \mathrm{mmHg}$ & $331(89.7 \%)$ \\
\hline Blood Glucose Measurements: & $38(10.3 \%)$ \\
RBG < 200 mg/dl & $363(98.4 \%)$ \\
RBG $\geq 200 \mathrm{mg} / \mathrm{dl}$ & $6(1.6 \%)$ \\
\hline Smoking status: & $246(75.2 \%)$ \\
Non-smokers & $81(24.8 \%)$ \\
Smokers & \\
\hline Family history of CVD risk factors: & $59(15.9 \%)$ \\
DM only & $32(8.6 \%)$ \\
HTN only & $188(50.09 \%)$ \\
Both HTN and DM only & $62(16.8 \%)$ \\
Abnormal lipids & \\
\hline Body Mass Index: & $11(3.0 \%)$ \\
Underweight $\left(<18.5 \mathrm{~kg} / \mathrm{m}^{2}\right)$ & $161(43.6 \%)$ \\
Normal $\left(18.5-24.9 \mathrm{~kg} / \mathrm{m}^{2}\right)$ & $111(30.1 \%)$ \\
Overweight $\left(25-29.9 \mathrm{~kg} / \mathrm{m}^{2}\right)$ & $59(16.0 \%)$ \\
Obese class I $\left(30-34.9 \mathrm{~kg} / \mathrm{m}^{2}\right)$ & $15(4.1 \%)$ \\
Obese class II $\left(35-39.9 \mathrm{~kg} / \mathrm{m}^{2}\right)$ & $12(3.3 \%)$ \\
Obese Class III $\left(\geq 40 \mathrm{~kg} / \mathrm{m}^{2}\right)$ & \\
&
\end{tabular}


ejhm.journals.ekb.eg

Table 2: Variables associated with the gender on Univariate analysis

\begin{tabular}{|l|l|l|}
\hline Variables & $\begin{array}{l}\text { Male n=267 } \\
\text { (\% within gender) }\end{array}$ & $\begin{array}{l}\text { Female } \mathbf{n}=102 \\
\text { (\% within gender) }\end{array}$ \\
\hline Body Mass Index & & \\
\hline $\mathrm{BMI} \geq 25 \mathrm{~kg} / \mathrm{m}^{2}$ & $133(49.8 \%)$ & $64(62.7 \%)$ \\
\hline $\mathrm{BMI}<25 \mathrm{~kg} / \mathrm{m}^{2}$ & $134(50.2 \%)$ & $38(37.3 \%)$ \\
\hline Smoking status & & \\
\hline Current smoker & $79(29.7 \%)$ & $2(2.0 \%)$ \\
\hline Non-smoker & $187(70.3 \%)$ & $100(98.0 \%)$ \\
\hline Blood Pressure & & \\
\hline SBP $\geq 140$ and $/$ or DBP $\geq 90$ & $29(10.9 \%)$ & $9(8.8 \%)$ \\
\hline SBP/DBP $<140 / 90$ & $238(89.1 \%)$ & $93(91.2 \%)$ \\
\hline
\end{tabular}

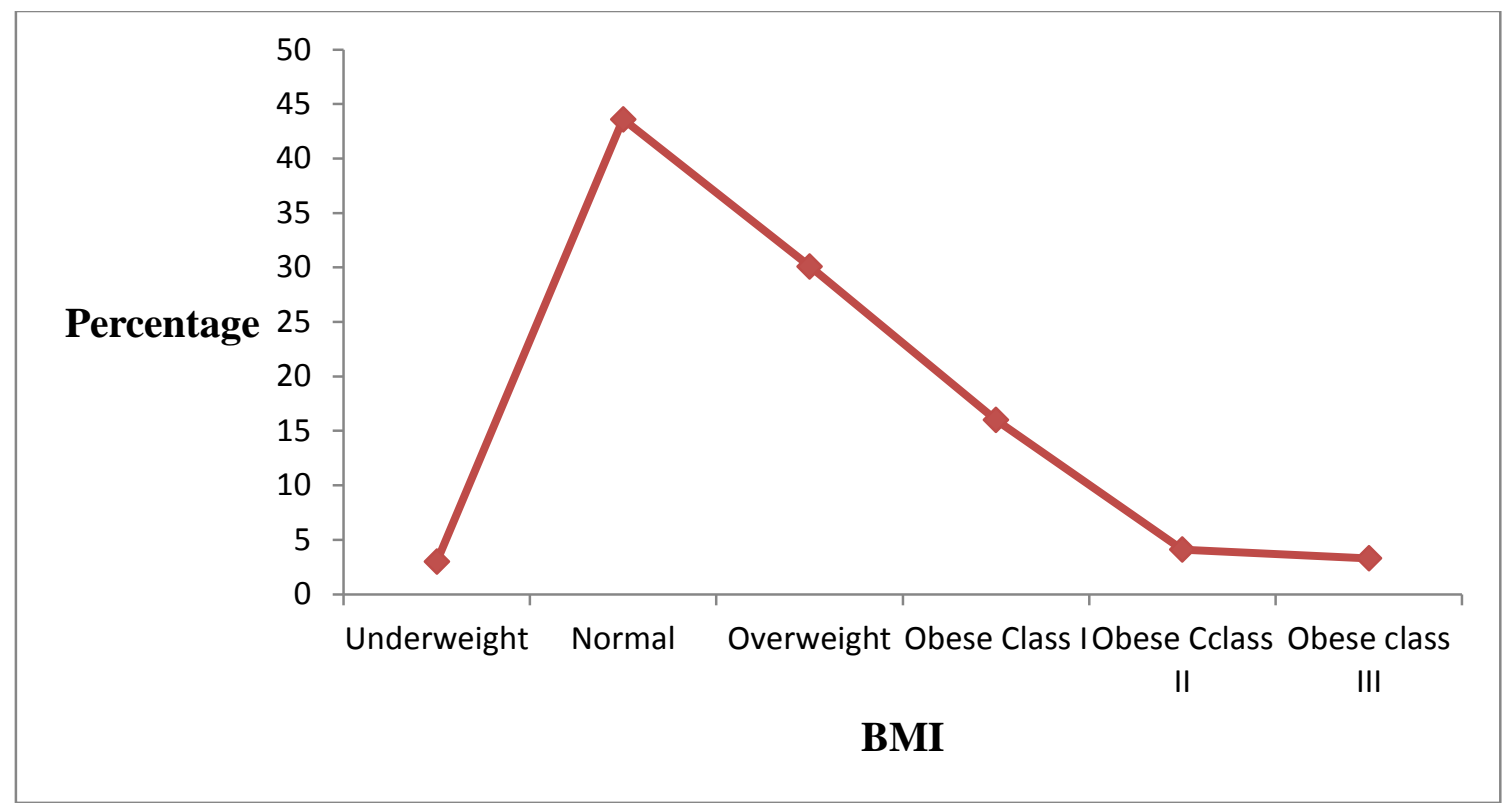

Figure 1: Body Mass Index of the participants

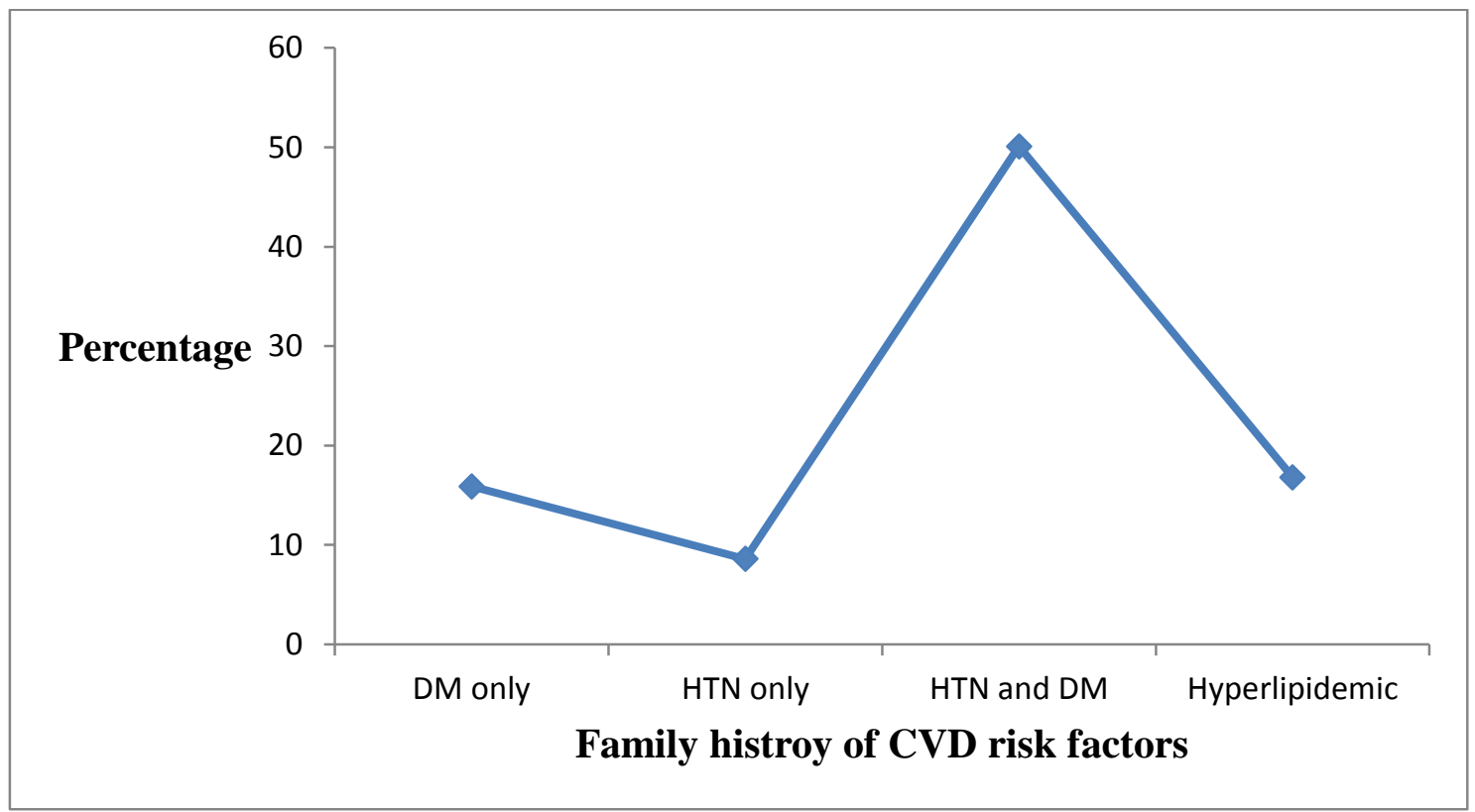

Figure 2: Family history of CVD risk factors 


\section{DISCUSSION}

Cardiovascular risk factors burden in the population of Saudi Arabia is quite high, with a previous national study showing almost half of the study cohort $(49.8 \%)$ having more than three cardiovascular risk factors with dyslipidemia being the highest factor followed by obesity, diabetes mellitus, and hypertension (18). Researchers from worldwide indicated high prevalence of CVD among the respective population which is nationwide growing problem ${ }^{(19)}$. In this study, we attempted to quantify the prevalence of cardiovascular risk factors in the community of Shaqra a rural city in the middle region of Saudi Arabia through personal medical history and actual measurements of BMI blood glucose and blood pressure to assess the existence of undiagnosed diseases in these participants. Participants with undiagnosed diabetes prevalence of $\mathrm{RBG} \geq 200 \mathrm{mg} / \mathrm{dL}^{[17]}$ was $6(1.6 \%)$. One study done in the western region of Saudi Arabia indicated a $1.3 \%$ prevalence of undiagnosed DM (20). An international study done in China in 2016 measuring the prevalence of undiagnosed HTN was $(21.3 \%)^{(21)}$ and a national survey was done in Saudi Arabia covering HTN awareness, treatment, and control which showed $14.1 \%$ of undiagnosed cases ${ }^{(22)}$. One of the most important risk factors which are obesity, shown to be a very common problem in our population and a red flag reaching up to $(53.38 \%)$ of the sample having an abnormal BMI $\geq 25 \mathrm{~kg} /$ $\mathrm{m}^{2}$. While obesity classes combined add up to (23.30\%) which are both really high when compared to the $36 \%$ prevalence of abnormal bodyweight representing the global burden ${ }^{(23)}$.

One study was done in the Saudi population in 2013 showing $57 \%$ prevalence of abnormal BMI ${ }^{(24)}$. One survey conducted nationally in Saudi Arabia covering males and females from the age of 15 and older that recruited 10,000 participants and found out that smoking prevalence was $(12.2 \%)^{(25)}$ and in another study done in 2010 in the eastern province indicated $(16.9 \%)$ were smokers ${ }^{(26,27)}$. Our study shows a higher prevalence of smoking in Shaqra population of $24.8 \%$.

\section{CONCLUSION}

It is obvious from the results of this study that cardiovascular disease risk factors are very common among the population of Shaqra, thus campaigns to raise the awareness of CVD risk factors and provide ways to combat it while encouraging annual medical check-ups to promote health to lead a wholesome life unburdened by illness.

\section{Conflict of Interest:None}

\section{ACKNOWLEDGMENT:}

We would like to extend our thanks to Sami Abdullah Aljabar and Abdullah Mohammed Almajed for their participation in the data collection and Shaqra University, Saudi Arabia for encouraging the researcher.

\section{REFERENCES}

1. World Health Organization. Global status on noncommunicable diseases (2014): Geneva, Switzerland: WHO; 2014 available from http://www.who.int/nmh/publications/ncd-status-report2014/en/

2. Mendis, Shanthi, Puska, Pekka, Norrving, B, World Health Organization, World Heart Federation. et al. (2011: Global atlas on cardiovascular disease prevention and control. World Health Organization. Available from: https://apps.who.int/iris/handle/10665/44701

3. Lozano R, Naghavi M, Foreman K, Lim S, Shibuya K, Aboyans V, Abraham J., et al. (2012): Global and regional mortality from 235 causes of death for 20 age groups in 1990 and 2010: a systematic analysis for the Global Burden of Disease Study 2010. Lancet, 380(9859): 2095-2128.

4. D'Agostino R, Vasan R, Pencina M et al. (2008): General cardiovascular risk profile for use in primary care: the Framingham heart study. Circulation, 117(6): 743-753.

5. Smith SC (2007): Multiple risk factors for cardiovascular disease and diabetes mellitus. Am J Med.,120(3 Suppl 1): S3-S11.

6. Mendis S (2010): The contribution of the Framingham Heart Study to the prevention of cardiovascular disease: a global perspective. Progress in Cardiovascular Diseases, 53(1): 10-14.

7. Yusuf S, Reddy S, Ounpuu S, Anand S (2001): Global burden of cardiovascular diseases: part I: general considerations, the epidemiologic transition, risk factors, and impact of urbanization. Circulation., 104(22): 27462753.

8. Ofori SN, Odia OJ (2015): Risk assessment in the prevention of cardiovascular disease in low-resource settings. Indian Heart J., 68(3): 391-398.

9. Aljefree N, Ahmed F (2015): Prevalence of cardiovascular disease and associated risk factors among adult population in the Gulf region: a systematic review. Advances in Public Health, 2015: 23.

10.World Health Organization (2018): Noncommunicable Diseases (NCD) Country Profiles. Available from: https://www.who.int/nmh/countries/sau_en.pdf

11.Al-Shahri MZ. (1996): Health and lifestyle: a Saudi profile. J Family Community Med., 3(2): 13-21.

12. Midhet F, Al Mohaimeed AR, Sharaf F (2010): Dietary practices, physical activity and health education in Qassim region of Saudi arabia. Int J Health Sci., 4(1): 3-10.

13. Alharthi F, Alrahimi J, Alotaibi A, Alhamdi D, Ibrahim B, Badeeb Y (2017): Prevalence of Undiagnosed Cardiovascular Risk Factors in Adults Aged 20-40: A Cross-Sectional Study in 2016 in Jeddah, Saudi Arabia. Cardiology Research., 8(3): 111-116.

14.Pickering TG, Hall JE, Appel LJ et al. (2005): Recommendations for blood pressure measurement in 
humans and experimental animals: Part 1: blood pressure measurement in humans: a statement for professionals from the Subcommittee of Professional and Public Education of the American Heart Association Council on High Blood Pressure Research. Hypertension, 45(1): 142-161.

15.James PA, Oparil S, Carter BL et al. (2014): Evidence-based guideline for the management of high blood pressure in adults: report from the panel members appointed to the Eighth Joint National Committee (JNC 8) JAMA., 311(5): 507-520.

16. WHO(2000): Obesity preventing and managing the global epidemic. World Health Organ Tech Rep Ser., 894: i-xii. 1-253.

17. World Health Organization(2006): Definition and Diagnosis of Diabetes Mellitus and Intermediate Hyperglycaemia . https://www.who.int/diabetes/publications/diagnosis_di abetes2006/en/

18. Ahmed AM, Hersi A, Mashhoud W et al. (2017): Cardiovascular risk factors burden in Saudi Arabia: The Africa Middle East Cardiovascular Epidemiological (ACE) study. J Saudi Heart Assoc., 29(4): 235-243.

19. Wu J, Cheng X, Qiu L et al. (2016): Prevalence and Clustering of Major Cardiovascular Risk Factors in China: A Recent Cross-Sectional Survey. Medicine (Baltimore), 95(10): e2712.

20.Bahijri SM, Jambi HA, Al Raddadi RM, Ferns G, Tuomilehto J (2016): The Prevalence of Diabetes and Prediabetes in the Adult Population of Jeddah, Saudi Arabia - A Community-Based Survey. PLoS One, 11(4): $\mathrm{e} 0152559$.

21.Zhang H, Deng M, Xu H, Wang H, Song F, Bao C, Paillard-Borg S, Xu W, Qi X (2017): Pre and undiagnosed-hypertension in urban Chinese adults: a population-based cross-sectional study. Journal of Human Hypertension, 31(4): 263-269.

22. Saeed AA, Al-Hamdan NA, Bahnassy AA, Abdalla AM, Abbas MA, Abuzaid LZ (2011): Prevalence, awareness, treatment, and control of hypertension among Saudi adult population: a national Survey. Int J Hypertens., 2011: 174135.

23.Ng M, Fleming T, Robinson M et al. (2014): Global, regional, and national prevalence of overweight and obesity in children and adults during 1980-2013: a systematic analysis for the Global Burden of Disease Study 2013. Lancet, 384(9945): 766-781.

24. Memish ZA, El Bcheraoui C, Tuffaha M, Robinson M, Daoud F, Jaber S, Mikhitarian S et al. (2014): Obesity and associated factors - Kingdom of Saudi Arabia, 2013. Prev Chronic Dis., 11: E174.

25. Moradi-Lakeh M, El Bcheraoui C, Tuffaha M, Daoud F, Al Saeedi M, Basulaiman M, Memish ZA et al. (2015): Tobacco consumption in the Kingdom of Saudi Arabia, 2013: findings from a national survey. BMC Public Health, 15: 611.

26. Al-Turki KA, Al-Baghli NA, Al-Ghamdi AJ, ElZubaier AG, Al-Ghamdi R, Alameer MM (2010): Prevalence of current smoking in Eastern province, Saudi Arabia. East Mediterr Health J., 16: 671-676.

27. Balkau B, Shipley M, Jarrett RJ, Pyorala K, Pyorala M, Forhan A, Eschwege E (1998): High blood glucose concentration is a risk factor for mortality in middleaged nondiabetic men, 20-year follow-up in the Whitehall Study, the Paris Prospective Study, and the Helsinki Policemen Study. Diabetes Care, 21(3): 360367. 